EESTI NSV TEADUSTE AKADEEMIA TOIMETISED. GEOLOOGIA

НЗВЕСТИЯ АКАДЕМИН НАУК ЭСТОНСКОН ССР. ГЕОЛОГИЯ

PROCEEDINGS OF THE ACADEMY OF SCIENCES OF THE ESTONIAN SSR. GEOLOGY

$1986,35,2$

удК $550.42: 552.3 / 5+551.732(474)$

Л. БИТЮКОВА

\title{
ОСНОВНЫЕ ЗАКОНОМЕРНОСТИ РАСПРЕДЕЛЕНИЯ МАЛЫХ ЭЛЕМЕНТОВ В ТЕРРИГЕННЫХ ОТЛОЖЕНИЯХ ВЕНДА И КЕМБРИЯ СЕВЕРНОЙ ПРИБАЛТИКИ
}

Многочисленными работами в области геохимии осадочных пород (Акульшина, 1971; Геохимия..., 1980; Пачаджанов, 1981 и др.) показана возможность использования малых элементов в качестве индикаторов условий формирования осадочных пород, в частности физикогеографической обстановки осадкообразования.

Осадочные породы венда и кембрия Северной Прибалтики, представленные терригенными отложениями, накапливавшимися в условиях гумидного типа литогенеза в самые ранние эпохи формирования осадочного чехла северо-западной части Восточно-Европейской платформы, особенно интересны для решения подобных задач, поскольку образование их происходило в ходе неоднократной смены знака тектонических движений, чередования периодов преобладания привноса слабопереработанного кластогенного материала и переотложения образований ранее сформировавшихся осадочных толщ, изменения фациальных условий в ходе седиментационных циклов. Главными типами пород венда и кембрия Северной Прибалтики являются глины, алевролиты и песчаники, на долю которых приходится, согласно расчетам Э. Пирруса (1970), соответственно $40,8,34,0$ и $25,2 \%$.

Учитывая хорошую литологическую изученность этих древнейших отложений платформенного этапа осадконакопления на территории Северной Прибалтики, следует отметить, что их геохимические особенности изучены несколько слабее.

Для получения общей геохимической характеристики осадочных отложений и установления индикаторной роли микроэлементов было проведено детальное опробование изучаемых отложений и рассмотрено распределение микроэлементов в вышеназванных типах пород. Геохимическое сопоставление основных стратиграфических подразделений сравнение содержаний элементов в литологически однотипных, но разновозрастных породах, а также сравнение их главных типов внутри каждого стратиграфического подразделения проводилось с учетом основных параметров распределения на основании критерия Стьюдента. Все это позволило выделить элементы, накопление которых присуще определенным этапам осадкообразования в венде и кембрии.

Распределение микроэлементов, являясь функцией внутренних и внешних факторов миграции, отражает изменение условий и обстановок осадконакопления и, как следствие, его рассмотрение ведет к выявлению элементов, типичных для отложений определенных уровней изучаемого разреза. Это относится и к отложениям венда и кембрия изучаемого региона, в распределении элементов в которых, как видно из рисунка, находят отражение изменения как тектонической обстановки региона, так и особенностей миграционного переноса элементов, находящихся в зависимости от физико-географических условий развития региона. 

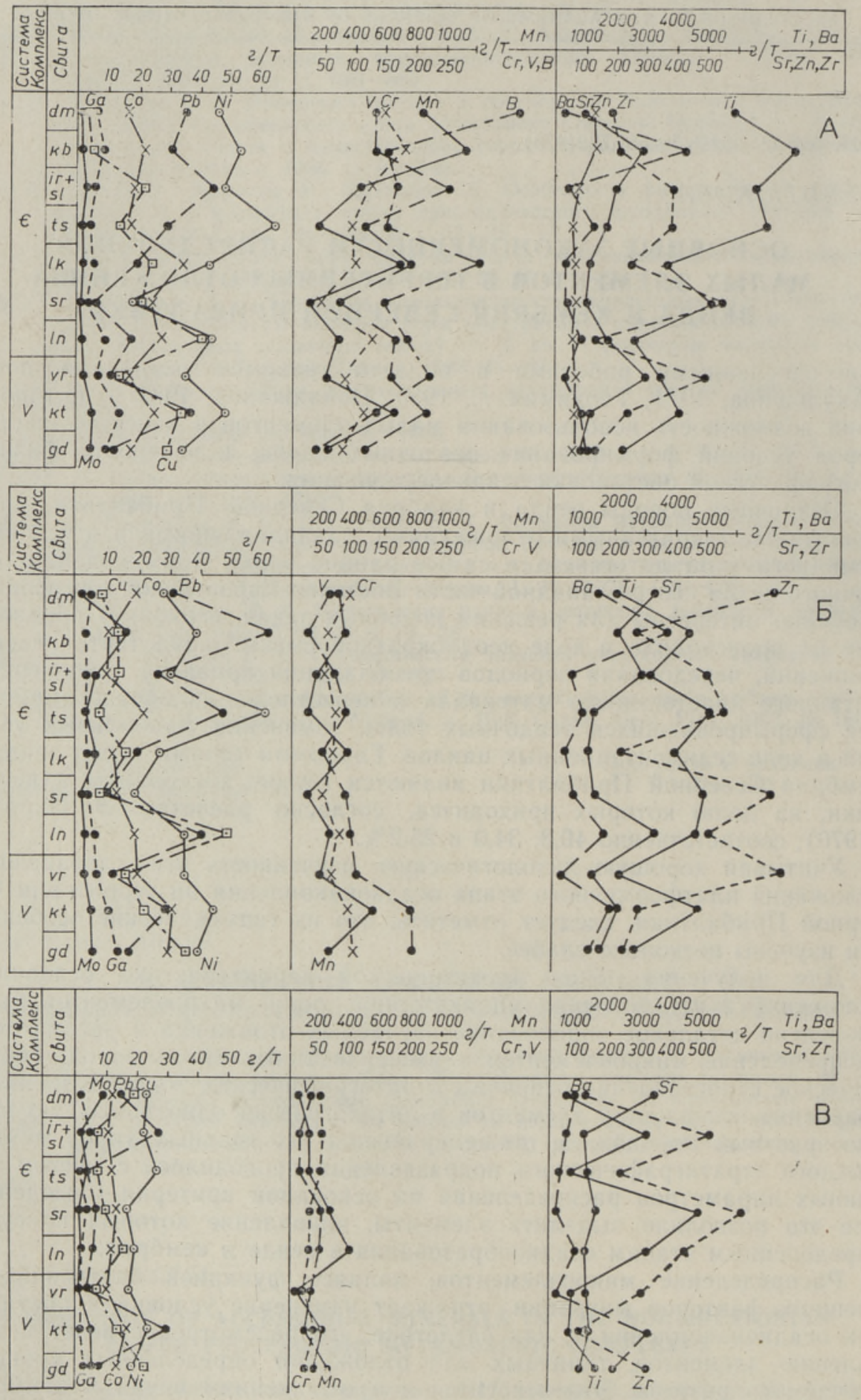

Распределение элементов в главных типах пород венда и кембрия Северной Прибалтики. А - глины; Б - алевролиты; В - песчаники. 


\section{Венд}

Вендская часть разреза, представленная отложениями четко выраженгого единого цикла седиментации, включает образования всех его фаз.

Отложения начальной стадии трансгрессии - гдовской свиты, залегающие на ннтенсивно разрушенных породах кристаллического фундамента и формировавшиеся непосредственно за их счет, отличаются значительным содержанием в составе глинистых минералов каолинита, достигающего $50 \%$ по Э. Пиррусу (1970). В отложениях вендского этапа осадконакопления происходит изменение соотношения основных глинистых минералов (каолинита, гидрослюд, хлорита). В котлинской свите содержание каолинита падает (до $15-25 \%$ ), при этом роль гидрослюд возрастает (до $80 \%$ ). В глинистых породах, завершающих вендский цикл осадконакопления - отложениях воронковской свиты содержание каолинита вновь увеличивается до $70 \%$. Однако, попытка установить зависимость между содержаниями микроэлементов и минералогическим составом глин не привела к положительным результатам как для отложений вендского цикла седиментации, так и для отложений изучаемого разреза в целом.

Близость источника сноса, интенсивное разрушение пород и быстрый темп осадконакопления в гдовское время обусловили полимиктовый состав песчаников и алевролитов и привели к отсутствию четкой дифференциации химических элементов между основными типами пород. Значимо более высокие содержания на основе $t$-критерия устанавливаются в алевролитах по сравнению с песчаниками для $\mathrm{Cr}$, Co, $\mathrm{Ni}, \mathrm{V}, \mathrm{Cu}$ и $\mathrm{Ga}$. Содержания малых элементов в глинах и алевролитах весьма близки, статистически значимые различия устанавливаются лишь для $\mathrm{Co}, \mathrm{V}$ и $\mathrm{Zr}$ (их содержания более высокие в алевролитах).

Дальнейшая переработка исходного материала в период трансгрессивного максимума (котлинская свита), повлекла за собой как механическую дифференциацию, так и поступление элементов за счет разрушения малоустойчивых минералов. Тенденция к накоплению в отложениях данного возраста отмечается для подавляющего большинства рассматриваемых элементов, за исключением Ва; значимое увеличение содержаний по сравнению с образованиями гдовской свиты установлено для $\mathrm{Cr}, \mathrm{Co}, \mathrm{Ni}, \mathrm{V}, \mathrm{Mn}, \mathrm{Pb}, \mathrm{Sr}, \mathrm{Ti}$ (в глинах), Mn, Pb, Ba, Ti (в алевролитах) и $\mathrm{V}, \mathrm{Pb}, \mathrm{Zr}, \mathrm{Ga}$ (в песчаниках). Таким образом, в котлинской свите устанавливается другой характер распределения элементов между основными типами пород - он приобретает черты упорядоченности. Песчаники четко отличаются минимальным содержанием большинства элементов, по сравнению с алевролитами они значимо беднее $\mathrm{Cr}$, Co, $\mathrm{Ni}, \mathrm{V}, \mathrm{Mn}, \mathrm{Zr}$, Ga, Ti, глины имеют более высокие содержания Cu, Ba и $\mathrm{Sr}$.

Отложения воронковской свиты, завершающей трансгрессивнорегрессивный вендский цикл седиментации, и формировавшиеся, судя по минеральной зрелости как обломочного, так и глинистого компонентов, за счет осадочных образований нижележащих свит, характеризуются значимыми понижениями средних содержаний большинства микроэлементов, за исключением лишь связанных с наиболее устойчивыми минералами $\mathrm{Ti}$ и $\mathrm{Zr}$. По сравнению с отложениями нижезалегающей котлинской свиты воронковские глины значимо беднее $\mathrm{Cr}, \mathrm{Co}$, $\mathrm{Ni}, \mathrm{Mn}, \mathrm{Pb}, \mathrm{Cu}, \mathrm{Mo}, \mathrm{Ga}, \mathrm{Ba}$ и $\mathrm{Sr}$, алевролиты - $\mathrm{Cr}, \mathrm{Co}, \mathrm{Mn}, \mathrm{Pb}, \mathrm{Ba}$ и $\mathrm{Ti}$, песчаники - $\mathrm{Co}, \mathrm{Mn}, \mathrm{Pb}, \mathrm{Cu}, \mathrm{Mo}, \mathrm{Ba}$.

Наблюдается дальнейшее усиление степени упорядоченности в распределении микроэлементов (обеднение ими песчаных фракций пород при фиксации в глинах), являющееся результатом неоднократной переработки поступавшего в бассейн седиментации материала. 
В целом же для вендского цикла осадконакопления характерна закономерная приуроченность максимальных средних содержаний к отложениям котлинской свиты для всех рассматриваемых типов пород по сравнению с образованиями начальной и завершающей стадий цикла. Более грубозернистые отложения, в первую очередь песчаники и алевролиты, по содержанию микроэлементов различаются миннмально, причем значимые различия практически стираются в песчаниках, наблюдается лишь увеличение содержаний $\mathrm{Ni}$.

\section{Кембрий}

Формирование кембрийских отложений, представленных образованиями нескольких седиментационных циклов, на изучаемой территории началось с накопления отложений лонтоваского горизонта (лонтоваской и воозиской свит) и происходило в условиях значительного увеличения площади седиментационного бассейна и вовлечения в осадочный цикл разрушаемых пород коры выветривания фундамента, что нашло свое отражение и в изменении содержаний микроэлементов в основных типах пород. Отмечается статистически значимое увеличение содержаний $\mathrm{Cr}, \mathrm{Co}, \mathrm{Ni}, \mathrm{V}, \mathrm{Mn}, \mathrm{Pb}, \mathrm{Cu}, \mathrm{Zr}, \mathrm{Ba}, \mathrm{Sr}$ (в глинах), Cr, $\mathrm{Pb}, \mathrm{Cu}, \mathrm{Zr}, \mathrm{Ba}$, $\mathrm{Sr}$, Ti (в алевролитах), $\mathrm{Cr}, \mathrm{Co}, \mathrm{V}, \mathrm{Mn}, \mathrm{Cu}, \mathrm{Zr}, \mathrm{Ba}$ и $\mathrm{Ti}$ (в песчаниках) для отложений лонтоваского горизонта по сравнению с нижезалегающими отложениями воронковской свиты.

Однако в целом процесс разрушения пород кристаллического фундамента в лонтоваское время не сопровождался интенсивным химическим выветриванием (о чем говорит полимиктовый состав пород и почти полное отсутствие в них каолинита) и дифференциация обломочного материала в значительной степени определяла распределение элементов в гранулометрическом' спектре. Основная масса элементов мигрировала в форме изоморфных примесей в решетках разрушавшихся породообразующих минералов. Спокойное развитие трансгрессии, исключительно медленный темп осадконакопления и большая площадь басссйна обусловливали усиление процессов осадочной дифферен циации, что, в свою очередь, приводило к увеличению контрастности в распределении микроэлементов в породах данной свиты.

Так, алевролиты лонтоваского горизонта значимо богаче песчаников $\mathrm{Cr}, \mathrm{Co}, \mathrm{N}$, $, \mathrm{V}, \mathrm{Pb}, \mathrm{Cu}, \mathrm{Ga}, \mathrm{Ba}, \mathrm{Sr}$ и $\mathrm{Ti}$, а глины, по сравнению с алевролитами, - $\mathrm{Cr}$, Co, Ni, V и $\mathrm{Ga}$.

Существенные различия в содержаниях микроэлементов прнсущи отложениям лонтоваского горизонта в базальной части следующего цикла седиментации (ливской серии) - сыруской свите. Так, глиғы последней имеют значимо более низкие содержания $\mathrm{Cr}, \mathrm{Ni}, \mathrm{V}, \mathrm{Mn}, \mathrm{Pb}$, $\mathrm{Mo}, \mathrm{Ga}$ и $\mathrm{Sr}$, алевролиты - $\mathrm{Ni}, \mathrm{Cu}, \mathrm{Ga}$ и $\mathrm{Sr}$, а песчаники - $\mathrm{Cu}$ и $\mathrm{Ba}$.

Формирование сыруской свиты происходило в период интенсивного вовлечения в процесс седиментогенеза новых порций обломочного материала за счет разрушасмых на западе региона коренных пород. Этот материал отличался низкой степенью переработки (сохранностью ряда мало- и среднеустойчивых минералов - полевых шпатов, эпидота, амфиболоз, бурого биотита), с преобладанием в кгчестве ведущей формы миграции элементов взвесей низкой степени дисперсности. И, как следствие, статистически значимые различия содержаний микроэлементов в основных типах пород этой свиты практически отсутствуют. Они установлены лишь для элементов с четко выраженным преобладанием одной из миграционных форм. Так, наблюдается увеличение содержаний $\mathrm{Cu}$ в глинах, $\mathrm{Ba}, \mathrm{Cr}-$ в песчаниках, V и $\mathrm{Mn}-$ в алевролитах, 
Характер распределения элементов в люкатиской свите, перекрывающей на основной части изучаемой территории отложения лонтоваской свиты, отражает их генетическое родство и близость минерального состава. По средним содержаниям большинства микроэлементов они весьма близки. Однако процесс переработки и переотложения привел к некоторому обогашению люкатиских глин Co, Mn, $\mathrm{Zr}$, Ti, В и обеднению $\mathrm{Cr}, \mathrm{Cu}, \mathrm{Ga}, \mathrm{Ba}$ и $\mathrm{Sr}$, поскольку выветривание и размыв с последующим переотложением сопровождались разрушением минералов, усилением роли в миграции элементов тонких взвесей и растворов, что привело к повышению средних содержаний элементов в наиболее тонкодисперсных образованиях.

Для алевролитов этих свит различия в содержаниях менее существенны (в люкатиской свите более высокие содержания $\mathrm{Mn}$, Мо) и обусловлены в значительной степени лишь усилением механической дифференциации осадочного материала.

Отличительной чертой отложений люкатиской свиты по сравнению с нижезалегающими кембрийскими образованиями является увеличение контрастности в распределении элементов между основными типами пород этой свиты - резкое возрастание степени упорядоченности. Так, в глинах наблюдаются более высские содержания практически всех изучаемых элементов (за исключением Мо и Ті): При этом статистически значимое по $t$-критерию увеличение установлено для $\mathrm{Cr}, \mathrm{Co}, \mathrm{Ni}$, $\mathrm{V}, \mathrm{Mn}, \mathrm{Cu}, \mathrm{Ga}$ и $\mathrm{Ba}$.

Формирование венчающих ливскую серию пород тискреской свиты, накапливавшихся в явно регрессивный этап развития территории, происходило, главным образом, за счет перемыва нижележащих, а также, в некоторой степени, сноса новых порций кластогенного материала при незначительном расширении областей питания. Об этом свидетельствуют особенности минерального состава - увеличение роли турмалина, полевых шпатов и менее устойчивых разновидностей слюд (Менс, Пиррус, 1972; Менс, 1979). Снос терригенного материала оказывал весьма значительное влияние и на характер распределения микроэлементов в отложениях свиты. В частности, содержания основного числа микроэлементов в глинах тискреской свиты ниже, чем в нижележащих глинистых породах. Статистически значимое уменьшение наблюдается для $\mathrm{Co}, \mathrm{V}, \mathrm{Mn}$ и $\mathrm{Cu}$ - т. е. для элементов, мигрирующих обычно в форме растворов нли наиболее тонких взвесей. Увеличение средних содержаний в глинах отмечается лишь у элементов, поступающих главным образом с терригенным материалом - $\mathrm{Pb}, \mathrm{Ni}, \mathrm{Ba}, \mathrm{Sr}, \mathrm{Zr}$ и Ti. Здесь выделяются как элементы, связанные с нанболее устойчивыми минералами $(\mathrm{Ti}, \mathrm{Zr})$, так и элементы, обязанные свонм присутствием вхождению в виде изоморфной примеси в малоустойчивые, присутствующие в слаборазложенном кластогенном материале, минералы.

Влияние на состав формирующихся пород поступления кластогенного материала в еще большей степени находит свое отражение в алевролитах, составляющих основную часть отложений данной свиты. В данном типе пород тенденция к увеличению содержаний наблюдается для основного числа рассматриваемых элементов - $\mathrm{Cr}, \mathrm{Co}, \mathrm{Ni}, \mathrm{V}, \mathrm{Mn}, \mathrm{Pb}$, $\mathrm{Zr}, \mathrm{Ba}, \mathrm{Sr}, \mathrm{Ti}$, статистически значимые отличия установлены для Co, $\mathrm{Ni}, \mathrm{Mn}, \mathrm{Pb}, \mathrm{Zr}, \mathrm{Ba}, \mathrm{Ti}$.

При сравнении между собой основных типов пород тискреской свиты отмечается значимое обогащение глин по отношению $\mathrm{k}$ алевролитам $\mathrm{V}, \mathrm{Mn}, \mathrm{Cu}$ и Ti, в то же время они значимо беднее Со и Рb. Песчаники по сравнению с алевролитами значительно беднее микроэлементами, хотя по минеральному составу они близки к крупнозернистым алевролитам. Статистически значимое уменьшение содержаний в песчаниках установлено для $\mathrm{Co}, \mathrm{Ni}, \mathrm{V}, \mathrm{Pb}, \mathrm{Zr}, \mathrm{Ga}, \mathrm{Ba}$ и $\mathrm{Ti}$, что может быть свя- 
зано с отличительной чертой состава песчаников - подавленным значением полевых шпатов и слюд в составе легкой фракции.

Накопление отложений следующего цикла седиментации - айсчяйской серии - связано с развитием на западе изучаемой территории Балтийской синеклизы и сопровождалось образованием олигомиктовых песчано-алевритовых пород. Процессы выветривания вели к сдвигу максимальных средних содержаний основного числа рассматриваемых элементов к наиболее тонкодисперсным разностям пород и накоплению элементов в глинах.

Отложения соэлаской и ирбенской свит, выполняющие разрез Балтийской синеклизы, при сравнении с более древними кембрийскими образованиями северо-востока изучаемой территории, отличает близкий уровень содержаний большого числа рассматриваемых элементов в глинах и песчаниках. Статистически значимое увеличение содержаний установлено в глинах лишь для элементов, миграция которых связана преимущественно с растворами и тонкими взвесями $(\mathrm{V}, \mathrm{Mn}, \mathrm{Pb})$. Песчаники же данных свит характеризуются более высокими по $t$-критерию содержаниями $\mathrm{Zr}, \mathrm{Ga}$, $\mathrm{Ti}$ и $\mathrm{Pb}$, в поступлении которых важную роль играет, главным образом, кластогенный материал. Более сложный характер имеет распределение элементов в алевролитах. В них установлены более высокие содержания $\mathrm{Mn}, \mathrm{Cu}, \mathrm{Sr}$, значимо меньше содержится $\mathrm{Co}, \mathrm{Ni}, \mathrm{Ba}$ и $\mathrm{Ti}$.

Сортировка взвешенных частиц в процессе их переноса и достаточно интенсивное химическое выветривание (о чем свидетельствует олигомиктовый состав песчано-алевритовых пород) привели к высокой степени дифференциации осадочного материала, и, как следствие, к выработке упорядоченного типа распределения элементов между основными типами пород данных отложений. Так, глины ирбенской и соэлаской свит имеют значимо более высокие по сравнению с алевролитами содержания $\mathrm{Cr}, \mathrm{Co}, \mathrm{Ni}, \mathrm{V}, \mathrm{Mn}, \mathrm{Pb}, \mathrm{Ga}$ и $\mathrm{Ti}$, алевролиты по сравнению с песчаниками - $\mathrm{Ni}, \mathrm{V}, \mathrm{Sr}$.

Отложения вышележащей кибартайской свиты представлены на изучаемой территории своими краевыми фациями и имеют явно регрессивный характер. При сравнении основных типов пород кибартайской свиты с нижезалегающими и вышележащими отложениями обращает на себя внимание менее контрастное отличие по содержанию микроэлементов глин и песчаников, хотя в целом в глинах кибартайской свиты наблюдается более высокий уровень содержания микроэлементов, нежели в ирбенской свите и вышележащей дейменаской толще среднего кембрия. По содержанию микроэлементов в разновозрастных алевролитах установлены статистически значимые различия для $\mathrm{Cr}, \mathrm{Ni}, \mathrm{Mn}, \mathrm{Ba}, \mathrm{Ti}$, a также для $\mathrm{Co}, \mathrm{Cu}, \mathrm{Sr}$ (по сравнению с алевролитами тискреской свиты) и $\mathrm{V}, \mathrm{Mo}, \mathrm{Sr}$ (по сравнению с алевролитами дейменаской толщи).

Отложения кибартайской свиты характеризует упорядоченный тип распределения элементов в основных типах пород. В глинах установлены более высокие по $t$-критерию содержания $\mathrm{Co}, \mathrm{Cr}, \mathrm{V}, \mathrm{Mn}, \mathrm{Ga}$, Ti по сравнению с алевролитами, хотя тенденция к накоплению в них отмечается и для $\mathrm{Ni}, \mathrm{Sr}, \mathrm{Ga}, \mathrm{Zr}$. При этом наблюдается повышение содержаний $\mathrm{Ga}, \mathrm{Zr}$ и $\mathrm{Ti}$ в глинистых разностях пород этой свиты, что вызвано интенсивным разрушением минералов-носителей этих элементов и миграцией их в форме растворов и тонких взвесей.

Отложения дейменаской толщи, завершающей разрез Балтийской синеклизы, литологически и палеонтологически слабо охарактеризованы и не имеют четкого стратиграфического расчленения. Толща характеризуется средними содержаниями элементов в глинах, весьма близкими к таковым в соответствующих отложениях нижезалегающей кибартай- 
ской свиты. Однако, глины дейменаской толщи значимо беднее Ва й $\mathrm{Sr}$, а алевролиты $\mathrm{Ni}, \mathrm{Pb}, \mathrm{Mo}, \mathrm{Zr}, \mathrm{Ba}$ и $\mathrm{Ti}$.

Как следует из распределения элементов в кембрийских отложениях, здесь, также как и в венде, сохраняются основные закономерности, в частности выдерживается комплекс элементов, присущих определенным фазам развития седиментационных бассейнов, хотя и не столь четко выраженный из-за отсутствия отложений всех фаз имевших место седиментационных циклов.

Характер распределения микроэлементов в вендо-кембрийских отложениях подтверждает отмечаемый в ряде работ факт (Дегенс, 1967; Акульшина, 1971 и др.), что для установления их индикаторных свойств в отложениях, формировавшихся в различной обстановке, наиболее результативным является изучение характера распределения элементов лишь в наиболее дисперсных образованиях — глинах, а в более грубодисперсных разностях положительных результатов, как правило, не дает. При этом следует отметить четкую приуроченность максимумов накопления ряда элементов ( $\mathrm{Cu}, \mathrm{Mn}, \mathrm{Pb}, \mathrm{Ni}, \mathrm{Cr})$ к образованиям этапов, соответствующих максимальному развитию трансгрессий и характеризующихся накоплением наиболее дисперсных отложений.

Довольно четко по увеличению содержания $\mathrm{Ti}$ и $\mathrm{Zr}$ в алевролитах и песчаниках маркируются этапы, связанные с периодами интенсивного поступления кластогенного материала. В глинах данная закономерность затушевывается вследствие способности данных элементов к некоторому накоплению в условиях интенсивного выветривания (Ронов, Мигдисов, 1965; Геохимия..., 1980) в тонких фракциях, составляющих значительное содержание в этих породах.

Резюмируя вышесказанное, можно отметить, что установленный характер распределения микроэлементов в разновозрастных отложениях, четкая приуроченность возрастания содержаний ряда из них к отложениям определенных этапов развития седиментационных бассейнов позволяют выделить в качестве элементов-индикаторов $\mathrm{Cu}, \mathrm{Co}, \mathrm{Ni}, \mathrm{Pb}$, $\mathrm{Mn}, \mathrm{Cr}, \mathrm{V}$ и использовать их при стратификации и корреляции вендокембрийского комплекса пород Северной Прибалтики.

\section{ЛИТЕРАТУРА}

Акульшина Е. П. Вещественный состав глинистой части пород палеозоя Сибирской и Русской платформ и его эволюция. Новосибирск, 1971.

Геохимия элементов-гидролизатов. М., 1980.

Дегенс Э. Т. Геохимия осадочных образований. М., 1967.

Менс К. Минералогическая и палеонтологическая характеристика соэлаской свиты. Изв. АН ЭССР. Геол., 1979, 28, № 4, 125-132.

Менс К., Пиррус Э. Новые данные о возрасте тискреских слоев по материалам северо-западных разрезов Эстонии. - Изв. АН ЭССР. Хим. Геол., 1972, 21 , № 3, 278-281.

Пачаджанов Д. Н. Геохимия красноцветных меловых отложений. М., 1981.

Пиррус Э. Закономерности распределения глинистых минералов в вендских и кембрийских отложениях Восточной Эстонии. - Изв. АН ЭССР. Хим. Геол., 1970, 19, № 4, 322-333.

Ронов А. Б., Мигдисов А. А. Основные черты геохимии элементов-гидролизатов в процессах выветривания и осадконакопления. - Геохимня, 1965, № 2, 131157. 


\section{MIKROELEMENTIDE JAOTUSE POHIJOONI POHJA-BALTIKUMI VENDI JA KAMBRIUMI TERRIGEENSETES SETTEKIVIMITES}

Artiklis on esitatud spektraalanalüüsi andmed 15 mikroelemendi jaotuse kohta PōhjaBaltikumi vendi ja kambriumi kivimites. On selgitatud nende jaotustüübid ja sisalduse muutumise seaduspära kivimitüüpide ja stratigraafiliste üksuste kaupa. Mitmete mikroelementide puhul on kindlaks tehtud nende sisalduse muutumise seos settetsükli eri faasidega, mis lubab neid kasutada indikaatorelementidena läbilōigete liigestamisel ja korreleerimisel.

\section{BITYUKOVA}

\section{MAIN FEATURES OF THE DISTRIBUTION OF THE TRACE ELEMENTS IN NORTH-EAST BALTIC VENDIAN AND CAMBRIAN TERRIGENOUS ROCKS}

15 trace elements have been studied by using spectral analysis. The paper deals with the differences in their content and distribution changes in Vendo-Cambrian sections of the northern part of the North-East Baltic considering the main stratigraphical units and rock types (the Figure).

It has been stated that changes in the vertical distribution of those trace elements were caused by the cyclical sedimentation in the basin. Thus, both the initial stage of the transgression as well as the regressive one is characterized by the increased content of $\mathrm{Ti}$ and $\mathrm{Zr}$, while the content of $\mathrm{V}, \mathrm{Cr}, \mathrm{Mn}$ and $\mathrm{Co}$ has decreased as compared with the deposits of the stable stage of the transgression.

The established regularities of distribution permit us to use some trace elements, and namely $\mathrm{Cr}, \mathrm{Co}, \mathrm{Ni}, \mathrm{Cu}, \mathrm{Pb}$ and $\mathrm{Mn}$, as indicator elements at the subdivision and correlation of the Vendo-Cambrian sections studied. 